\title{
ESTUDO DE FISSURAS E TRINCAS ACOMETIDAS EM ESTRUTURAS PRÉ-MOLDADAS
}

\author{
SILVA, LOHANNA \\ Estudante de graduação \\ Fundação Universidade Federal de Rondônia \\ Rondônia; Brasil \\ santoslohanna95@gmail.com \\ LIMA, JOÃO PAULO \\ Estudante de graduação \\ Fundação Universidade Federal de Rondônia \\ Rondônia; Brasil \\ joaopaulokw@gmail.com
}

\author{
LOPES, RADUAN \\ Professor Mestre \\ Rondônia; Brasil \\ raduan.krauser@unir.br \\ PIOVESAN, JAYNE \\ Professora Mestre \\ Centro Universitário São Lucas \\ Rondônia; Brasil \\ jayne.piovesan@saolucas.edu.br
}

Fundação Universidade Federal de Rondônia

\section{RESUMO}

O estudo das manifestações patológicas em estruturas de concreto se origina pelo avanço e crescimento acelerado da construção civil. A necessidade de inovação traz consigo maiores riscos, com as inevitáveis falhas construtivas, o envelhecimento natural da estrutura, ou até mesmo má execução ou uso de materiais inadequados. As manifestações patológicas se apresentam em todos os meios da construção civil, mas a ênfase na parte estrutural deve ser tomada como primorial, uma vez que uma intervenção rápida pode provocar o colapso na edificação. Dentre as manifestações patológicas em estruturas, esse trabalho foca nas principais que podem acometer as estruturas pré-moldadas. Dentre as manifestações apresentadas as mais recorrentes nos sistemas pré-moldados são trincas e fissuras. Assim esse trabalho tem por objetivo, avaliar por meio de uma ampla revisão bibliográfica apresentar os principais motivos para o suurgimento de trincas e fissuras nas estruturas pré-moldadas e formas de se evitar o surgimento de tais manifestações patológicas.

Palavras-chave: pré-moldadas, manifestações patológicas, fissuras, trincas.

\section{ABSTRACT}

The study of pathological manifestations in concrete structures originates from the advancement and accelerated growth of construction. The need for innovation brings with its greater risks, with inevitable construction failures, the natural aging of the structure, or even poor execution or use inappropriate materials. Pathological manifestations are present in all construction sites, but the emphasis on the structural part must be taken as primary, as rapid intervention can cause the building to collapse. Among the pathological manifestation in structures, this work focuses on the main ones that can affect precast structures. Among the manifestations presented the most recurrent in precast systems are cracks and cracks. Thus, this paper aims to evaluate, through a broad literature review, to present the main reasons for the emergence of cracks and fissures in precast structures and ways to avoid the appearance of such pathological manifestations.

Keywords: precast, patholocial manifestation, fissures, cracks.

\section{INTRODUÇÃO}

As indústrias de pré-fabricados surgiram para atender os grandes avanços e crescimento da construção civil, a Associação Brasileira de Normas Técnicas, através da NBR 9062 (ABNT, 2017), define estrutura de concreto pré moldado como "elemento que é executado fora do local de utilização definitiva na estrutura, com controle de qualidade." Esse sistema construtivo, apresenta vantagens técnico-econômicas pois permitem o aperfeiçoamento em sua execução, na racionalização de seus materiais empregados e na qualidae do seu produto final. Apresentam características significativas que padronizam o sistema construtivo.

Para Souza e Ripper (1998), a patologia das estruturas pode ser definida como "o estudo das origens, formas de manifestação, consequências e mecanismos de ocorrência de falhas e dos sistemas de degradação das estruturas". As manifestações patológicas são oriundas de causas diversas, seja por erros de construção ou de projetos, algumas vezes podem não acarretar danos relevantes, como também podem apresentar grande comprometimento à estrutura. As 
manifestações mais recorrentes nos sistemas pré-moldados são fissuras e trincas. E são problemas que podem comprometer a vida útil da estrutura, assim como sua durabilidade.

Em algumas situações é possível identificar essas patologias apenas visualmente, porém em outras ocorrências torna-se necessário uma inspeção mais detalhada, como rever projetos básicos, analisar a forma de execução da obra, definir se a estrutura está sendo submetidas a cargas que não foram consideradas originalmente em seus cálculos estruturais e até mesmo executar ensaios para determinar se as anomalias reagem a estímulos ou se estão ativas na estrutura. Assim, torna-se possível definir um diagnóstico e apresentar as soluções para o seu devido reparo. Assim esse trabalho tem por objetivo analisar por meio de uma revisão bibliográfica as manifestações patológicas de fissuras e trincas em estruturas pré-moldadas.

\section{REVISÃO BIBLIOGRÁFICA}

\subsection{Estruturas de concreto pré-moldado}

Segundo El Debs (2017) a construção civil vem sendo a indústria que mais apresenta atraso, pois apresenta baixa produtividade, falta de controle tecnológico, mão de obra desqualificada e um grande desperdício de materiais de construção.

Sendo assim, tem-se buscado tecnologias para reduzir esse atraso, que seriam dispositivos associados a elementos prémoldados de concreto. As estruturas formadas por elementos pré-moldados são denominadas de estruturas de concreto pré-moldado, onde parte das construções são feitas em locais adequados com melhores condições e depois montadas em seu local definitivo, como parte do processo construtivo (EL DEBS, 2017).

A norma NBR 9062 (ABNT, 2017) também define pré-moldado como peças estruturais que são fabricadas em um molde e são levadas para serem curadas em área controlada que irá garantir a qualidade da peça e posterior transporte para a área de construção.

Esse tipo de construção apresenta inúmeras vantagens, como um menor prazo de execução, uma racionalização de materiais, limpeza e economia nos canteiros de obras e aumento do controle de qualidade. Mas para que todas essas vantagens possam ser potencializadas, é necessário que em sua concepção seja escolhida o tipo de estrutura mais adequado para a finalidade da edificação.

\subsubsection{Sistemas estruturais de concreto pré-moldado}

O sistema estrutural de concreto pré-moldado a princípio pode parecer simples quanto a sua forma de execução, mas as considerações de cálculo devem ser seguidas segundo cada tipo de sistema, assim algumas manifestações patógicas podem surgir em construções em concreto pré-moldado devido a falta de atenção ao sistema estrutural adotado. A seguir são apresentados os sistemas mais comuns para construção em concreto pré-moldado.

\subsubsection{Sistemas aporticados}

Segundo Van Acker (2002), esse sistema de vigas e pilares de diferentes tamanhos linearmente dispostos para formar pórticos, servem para alcançar grandes vãos sem a interferência de paredes. É muito utilizado para construções de armazéns, galeras comerciais, indústrias etc. A figura 1 apresenta um exemplo quanto ao sistema aporticado.

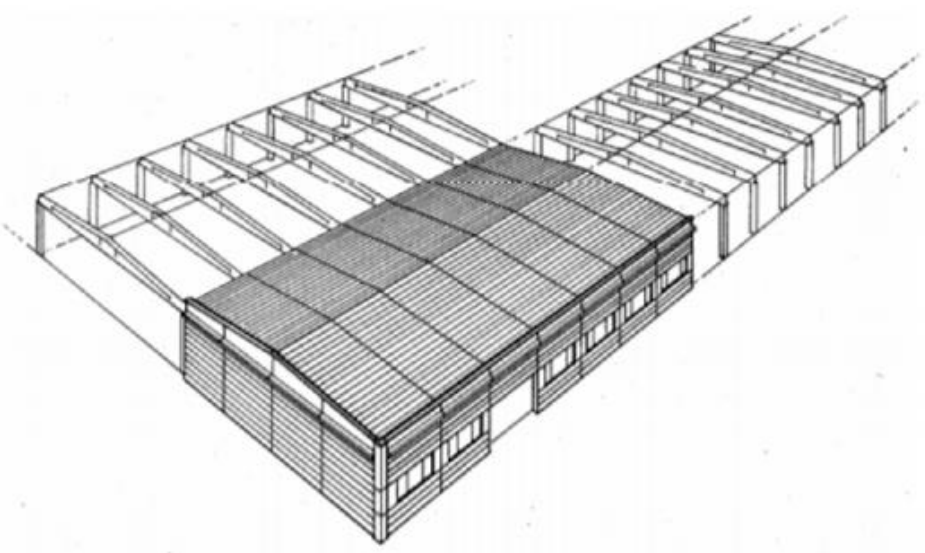

Figura 1: Sistema aporticado (Van Acker, 2002) 


\subsubsection{Sistema em esqueleto}

De acordo com Van Acker (2002) esse sistema se dispõe de vigas, pilares e lajes, combinados para formar o esqueleto da estrutura, para edificações de alturas médias e baixas. Oferece uma maior liberdade e flexibilidade para a disposições de áreas, usual para edificações de shoppings centers, construções industriais etc. A figura 2 apresenta um exemplo quanto ao sistema em esqueleto.

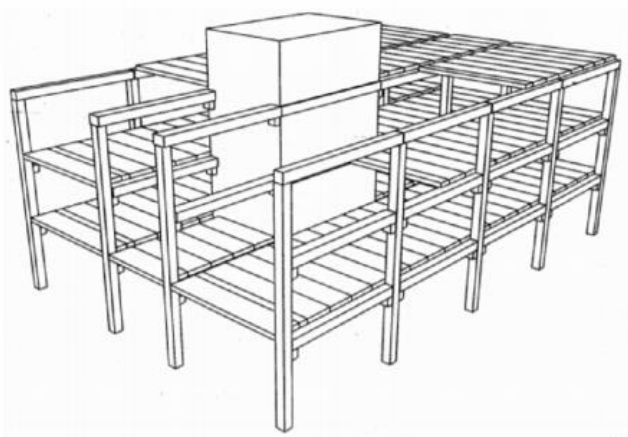

Figura 2: Sistema em esqueleto (Van Acker, 2002)

\subsubsection{Sistema de painéis estruturais}

Van Acker (2002) define que esse sistema pode ser utilizado para fechamentos estruturais ou de vedação. Oferem vantagem na rapidez, uma maior flexibilidade no uso dos espaços internos, podendo facilmente alterar seu layout. A figura 3 demonstra o sistema estrutural de paineis.

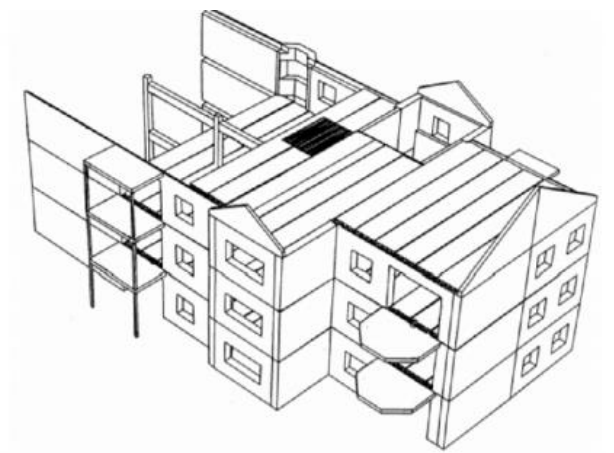

Figura 3: Sistema de painéis estruturais (Van Acker, 2002)

\subsubsection{Modulação nas estruturas pré-moldadas}

"A modulação é um fator econômico muito importante no projeto de construção de edifícios, tanto para o trabalho estrutural como para o acabamento." (Van Acker, 2002).

Para Van Acker (2002), essa modulação é ainda mais marcante em estruturas pré-moldadas, pois garantindo uma padronização de seus elementos, têm-se um sistema mais racional e uma economia na produção e execução. Também é de suma importância, que se observe os critérios estabelecidos em norma, pois nem sempre as dimensões especificadas no projeto serão iguais a construção final.

Para um projeto ser bem executado e minimizar as futuras manifestações patológicas é necessário conferir segurança às estruturas garantindo assim um desempenho satisfatório. Devem ser observados as exigências quanto à durabilidade das estruturas de concreto e a sua capacidade de resistir aos esforços solicitantes.

\subsubsection{Montagem das estruturas pré-moldadas}

Na montagem das estruturas pré-moldadas, de acordo com Doniak (2002) não apenas o controle de qualidade que deve ser levado em consideração, como também a logística do uso dos equipamentos para a montagem, visto que as peças pré-moldadas possuem bastante peso. Na montagem todos os elementos devem ser inspecionados no momento da 
descarga, afim de observar se houve danos no transporte ou içamento das peças. A seguir apresentam-se os processos da montagem das estruturas pre-moldadas:

- Montagem de pilares: os pilares são chumbados no bloco de fundação, respeitando o prumo e alinhamento;

- Montagem de vigas: as vigas podem ser apoiadas nos consolos dos pilares ou no apoio de outras vigas, sempre são montadas sobre os apoios;

- Montagem das lajes: O içamento das lajes são feitas por cabos e posicionadas nos apoios.

\subsection{Manifestações patológicas em estruturas pré-moldadas}

\subsubsection{Conceito de patologias}

As manifestações patológicas em edificações comprometem a sua vida útil. Entende-se como patologia, a área da engenharia que estuda as causas, diagnósticos e origens dos eventuais problemas que surgem nas estruturas e à terapia se resulta em corrigir e solucionar esses problemas patológicos, inclusive, aqueles que ocorrem devido ao envelhecimento natural (DEGUSSA, 2008).

De acordo com França (2010), a patologia das edificações pode ter origem na execução da obra, seja por falta de controle de qualidade ou por emprego inadequado de materiais, ou na elaboração do projeto básico ou adquiridas ao longo da sua vida útil. Gusmão (2013), determinou que os danos patológicos podem ser classificados em categorias, como demonstra a tabela 1 a seguir.

Tabela 1: Classificação dos danos patológicos (GUSMÃO, 2013).

\begin{tabular}{|c|c|c|}
\hline Danos & Características & Inconvenientes \\
\hline Estéticos & $\begin{array}{c}\text { São subjetivos e de efeitos } \\
\text { psicológicos. }\end{array}$ & $\begin{array}{c}\text { Sensação de insegurança, falta } \\
\text { de conforto e confiabilidade da } \\
\text { estrutura. }\end{array}$ \\
\hline Funcionais & $\begin{array}{c}\text { Comprometem o uso e } \\
\text { destinação da construção. }\end{array}$ & $\begin{array}{c}\text { Mau funcionamento dos } \\
\text { elementos da obra. }\end{array}$ \\
\hline Estruturais & $\begin{array}{c}\text { Afetam os elementos estruturais } \\
\text { da construção. }\end{array}$ & $\begin{array}{c}\text { Podem comprometer a } \\
\text { estabilidade da obra, pode exigir } \\
\text { reforço. }\end{array}$ \\
\hline
\end{tabular}

\subsubsection{Causas da deterioração das estruturas de concreto pré-moldado}

De acordo com Souza e Ripper (1998), ao identificar uma estrutura com danos patológicos, é necessário primeiramente entender e esclarecer os motivos e causas do desenvolvimento dessas doenças, e qual será a metodologia necessária para a sua cura.

O conhecimento das origens torna-se indispensável por não somente identificar as causas e tratá-las, mas garantir que a estrutura não volte a se deteriorar. A seguir no quadro 1 são apresentadas algumas classificações das causas dos processos de deterioração das estruturas.

Quadro 1: Classificações das causas de deterioração das estruturas (SOUZA E RIPPER, 1998).

\begin{tabular}{|l|l|l|}
\hline $\begin{array}{l}\text { Causas Intrínsecas } \\
\text { (inerentes a estrutura) }\end{array}$ & $\begin{array}{l}\text { Causas dos processos de } \\
\text { deterioração das estruturas }\end{array}$ & $\begin{array}{l}\text { Causas naturais próprias ao } \\
\text { material concreto }\end{array}$ \\
$\begin{array}{l}\text { Causas Extrínsecas } \\
\text { externas ao corpo }\end{array}$ & Ações externas \\
\hline
\end{tabular}

Souza e Ripper (1998) compreendem que as causas intrínsecas possuem sua origem na fase de execução da obra, seja por razões externas do ambiente, falhas humanas ou até mesmo uma má utilização dos materiais empregados. Já as causas extrínsecas não dependem da composição da estrutura, mas sim um fator externo que causa a sua deterioração, como falhas humanas durante o projeto ou na utilização, ações físicas, químicas e mecânicas.

2.3 Principais manifestações patológicas em edificações com estruturas de concreto pré-moldadas 


\subsubsection{Fissuras}

As fissuras, trincas, rachaduras e fendas diferem-se entre si através de suas espessuras. São classificadas conforme suas origens, em função de fenômenos físicos nas fases de construção ou se apresentam quando há um esforço solicitante maior que sua resistência inicial. Para cada uma delas existe uma solução e tratamentos adequados.

Para Oliveira (2012) "as fissuras podem ter suas causas como movimentação térmica, movimentação higroscópica, por atuação de sobrecargas, por deformação excessiva de estruturas, por recalque de fundações ou até por alterações químicas."

Quando o concreto está submetido ao esmagamento e ruptura frágil, é diagnosticado fissuras pelo efeito da compressão, já as fissuras de tração são as mais comumente. A seguir na tabela 2, são classificadas de acordo com Souza e Ripper (1998), as espessuras e tamanhos das aberturas, embora o processo para sua formação ocorra da mesma forma é necessário realizar essa qualificação.

Tabela 2: Espessuras das aberturas (SOUZA E RIPPER, 1998)

\begin{tabular}{|c|c|}
\hline Tipos de abertura & Tamanho \\
\hline Fissura capilar & Menos de $0,2 \mathrm{~mm}$ \\
\hline Fissura & De $0,2 \mathrm{~mm}$ a $0,5 \mathrm{~mm}$ \\
\hline Trinca & De $0,5 \mathrm{~mm}$ a $1,5 \mathrm{~mm}$ \\
\hline Rachadura & De $1,5 \mathrm{~mm}$ a $5 \mathrm{~mm}$ \\
\hline Fenda & De $5 \mathrm{~mm}$ a $10 \mathrm{~mm}$ \\
\hline Brecha & Mais de $10 \mathrm{~mm}$ \\
\hline
\end{tabular}

\subsubsection{Trincas}

Para Arivabene (2015), a trinca é um tipo de manifestação patológica mais perigosa que a fissura, por possuírem suas aberturas mais profundas e acentuadas. Para determinar com exatidão se é uma trinca, deve-se observar se o material que a trinca se encontra está separado em dois, ou seja, ela age como um divisor de suas partes. A figura 4, apresenta uma estrutura de concreto pré moldado com manifestação patológica de uma trinca.

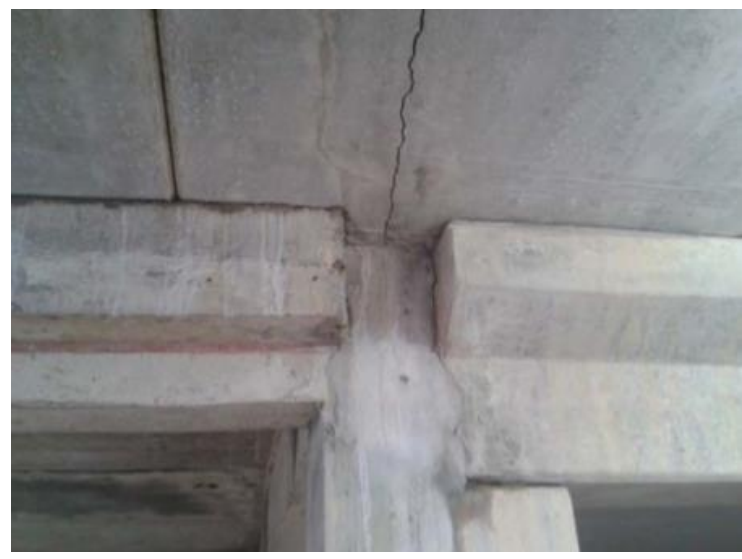

Figura 4: Trinca em estrutura pre-moldada (ARIVABENE, 2015)

\subsection{Principais fatores que ocasionam as manifestações patológicas}

\subsubsection{Movimentação térmica}

Souza e Ripper (1998) observaram que a origem de diferentes estados de tensão ou de sobretensão na peça estrutural como um todo, ou em partes, gerados por contração ou dilatação térmica, são condições favoráveis para o surgimento da fissuração em estruturas de concreto. Pois criam-se tensões superiores à sua capacidade.

Casotti (2007) também ressalta que os elementos estruturais planos, como lajes de cobertura, estão mais expostos a sofrerem movimentação térmica do que os parâmetros verticais da edificação. Pois normalmente esses elementos estão sofrendo mais solicitações e com intensidade mais bruscas.

2.4.2 Movimentação higroscópica 
As fissuras provocadas por variação de umidade dos materiais de construção são muito semelhantes àquelas provocadas pela variação de temperatura. As aberturas podem variar em função das propriedades higrotérmicas dos materiais e das amplitudes de variação da temperatura ou da umidade. (CASOTTI, 2007).

\subsubsection{Recalque de fundações}

De acordo com Souza e Ripper (1998) as edificações tendem a se deslocarem por um determinado período verticalmente, até atingirem seu equilíbrio no solo total. No entanto, falhas decorrentes de má concepção no projeto de fundações, contribuem para que a estrutura sofra com recalques diferenciais, no qual há um assentamento do solo fazendo com que a edificação fique em um ponto mais baixo que outro, ocasionando a abertura de trincas.

\subsubsection{Fissuras de tração pelo esforço de flexão}

Para Souza e Ripper (1998), a fissuração de tração pelo esforço de flexão ocorre quando há carregamento elevado ou a rigidez da peça ou a área de aço não é suficiente, ocasionando uma deformação excessiva. Como demonstra na Figura 5 a seguir, as fissuras originam da borda mais tracionada, erguendo-se até a altura da linha neutra.



Figura 5: Fissuras por tração em vigas (HELENE, 1992)

\subsubsection{Fissuras de compressão pelo esforço de flexão}

Helene (1992), esse efeito pode ser causado por sobrecargas não previstas inicialmente ou pela baixa resistência do concreto. A região comprimida entra em ruína por esmagamento, pois o elemento fletido ultrapassa a resistência à compressão do concreto. Esse tipo de fissuração é extremamente crítico, pois pode levar ao colapso da estrutura. A figura 6 apresenta exemplo quanto a compressão devido a flexão.

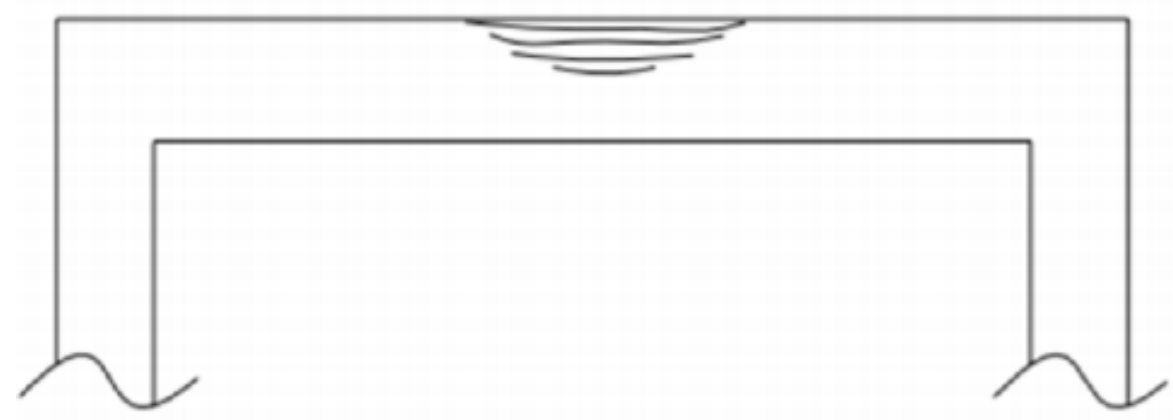

Figura 6: Fissuras de compressão pelo esforço de flexão (HELENE, 1992)

\subsubsection{Fissuras causada por esforço cortante}

Esse tipo de fissura é causado quando as tensões de compressão nas bielas geram tensões de tração perpendiculares a elas (HELENE, 1992). O conceito de bielas de compressão, vem da treliça generalizada de Morsch, onde elas são formadas por concreto e os estribos que são os montantes tracionados. 
Para evitar esse tipo de fissuração, a tensão de tração deve ser uma parte concentrada pelos estribos, e a outra pelo imbricamento e engrenamento dos agregados. Caso haja erro de projeto ou execução, essa armadura acaba não sendo suficiente ocasionado fissuras que formam ângulos de $35^{\circ}$ a $45^{\circ}$, conforme Figura 7 a seguir.

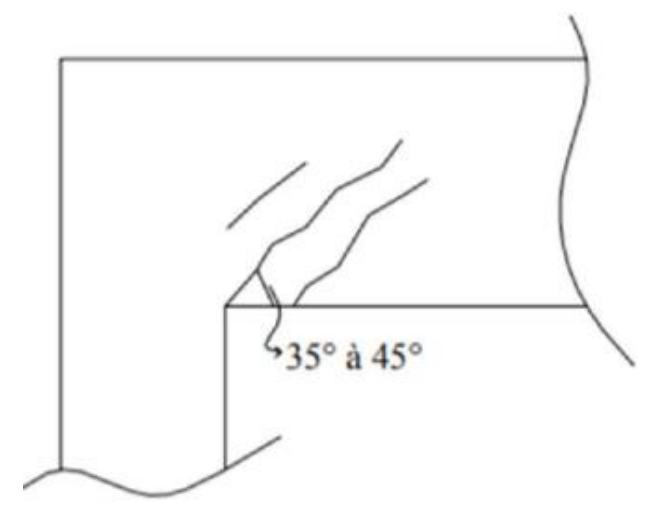

Figura 7: Fissuras pelo esforço cortante (HELENE, 1992)

\subsection{Identificação, tratamento e solução das fissuras}

Segundo Souza e Ripper (1998) para o tratamento adequado das peças fissuradas, é necessário a identificação de sua causa e origem, e verificar quanto a espessura da fissura está variando, e necessidade ou não de executar reforços estruturais. Quando uma estrutura apresenta problemas patológicos, primeiramente faz-se uma inspeção visual e após torna-se necessário uma vistoria com técnicos especializados para determinar a real condição da edificação, avaliando as patologias existente, definindo causas, e quais providências e métodos serão providenciados para remediar a situação e assim iniciar o tratamento e recuperação da estrutura.

Como apresentado, as fissuras podem ser classificadas em ativas ou passivas, no caso das ativas, é necessário criar-se uma barreira para que os gases nocivos não adentrem as fissuras, ocasionando a contaminação do concreto ou até das armaduras. Souza e Ripper (1998, p.21) descreve: "em se tratando de fissuras ativas, deve-se promover a vedação, cobrindo os bordos externos da mesma e, eventualmente, preenchendo-a com material elástico e não resistente. Deverá ser sempre uma obstrução macia, que admita e conviva com a patologia instaurada, impedindo, no entanto, a degradação do concreto".

Já as fissuras passivas, deve-se fechá-las injetando um material aderente e resistente, podemos citar como exemplo de acordo com Souza e Ripper (1998), uma resina epoxídica.

\subsubsection{Manutenção}

A NBR 5674 (2012) define manutenção como sendo o conjunto de atividades que possuem o objetivo de conservar ou recuperar a edificação, atendendo as necessidades e segurança dos seus usuários.

Quando se inicia a etapa de planejamento de uma obra, deve-se se atentar não somente para a forma de projetar e executar, como também o plano de manutenção em sua fase de execução e pós execução. Há três tipos de manutenções podendo ser: preventivas, corretivas e preditivas

Antunes (2004) define os tipos de manutenções como sendo: manutenção preditiva que tem o objetivo de analisar os sistemas e os equipamentos observando e apontando os problemas para direcionar o plano de manutenção preventivo; manutenção preventiva como a atividade que é realizada antes da necessidade da reparação e manutenção corretiva como aquela que visa a correção e solução de falhas.

\section{CONCLUSÃO}

As manifestações patológicas das estruturas pré-moldadas podem se originar por diversos fatores, sendo no processo de fabricação, transporte ou montagem, portanto a solução e recuperação dos elementos devem ser realizadas de forma eficiente, tornando o estudo da investigação, caracterização e diagnóstico indispensáveis.

As manifestações patológicas podem ser evitadas se os projetos básicos e complementares forem devidamente elaborados seguindo às normas técnicas vigentes, além do uso de materiais adequados e mão de obra técnica especializada. Um maior controle tecnológico, em cada etapa do processo de fabricação, transporte e montagem das estruturas de prémoldadas ajudam a minimizar ou resolvem definitivamente os problemas de patologias. Assim como, 
um planejamento do corpo técnico, especificando os produtos visando a maior vida útil possível da estrutura, definindo também um plano de inspeções periódicas e de manutenções preventivas.

Estruturas que possuem inspeções periódicas recebem um diagnóstico precoce, apresentando medidas de reparo e metodologias de execução mais simples e menos onerosa. Por isso toda edificação deve possuir um plano de manutenção eficiente garantindo a durabilidade da estrutura e aumento sua vida útil.

\section{REFERÊNCIAS}

ANTUNES, G. B. S. Estudo da manutenção de edifícios: percepções dos projetistas e gerentes/administradores. 2004. 228 p. Dissertação (Mestrado em Engenharia Civil), Universidade Federal do Espírito Santos. Vitória, 2004.

ARIVABENE, A C. Patologias em estruturas de concreto armado estudo de caso ISSN 2179-5568 - Revista Especialize On-line IPOG - Goiânia - Edição no 10 Vol. 01/2015 dezembro /2015.

ASSOCIAÇÃO BRASILEIRA DE NORMAS TÉCNICAS (ABNT). NBR 5674. Manutenção de Edifícios: requisitos para o sistema de gestão de manutenção. Rio de Janeira, 2012.

ASSOCIAÇÃO BRASILEIRA DE NORMAS TÉCNICAS (ABNT). NBR 9062: Projeto e execução de estruturas de concreto pré-moldado. Rio de Janeiro, 1985, rev. mar, 2017.

DEGUSSA. Manual de Reparo, Proteção e Reforço de Estruturas de Concreto. 2003. Ed. Red. Reabilitar. São Paulo, 2003.

DONIAK, Í. L. O Manual de montagem de pré-moldados ABCIC/NETPre. São Paulo, 2007.

EL DEBS, M. K. Concreto pré-moldado fundamentos e aplicações. São Paulo, Ed. Oficina de Textos, $2^{\mathrm{a}}$ ed., 2017, 456p.

FRANÇA, A. A.V.; MARCONDES, C. G. N.; ROCHA, F. C. Patologia das construções: uma especialidade na engenharia civil. Téchne, São Paulo, ed. 174, p. 72-77, set 2011.

GUSMÃO, A. D.. Patologias e reforço das fundações. Cuiabá, 2013.

OLIVEIRA, A. M. Fissuras, trincas e rachaduras causadas por recalque diferencial de fundações. Trabalho de Conclusão de Curso (Especialização) - Universidade Federal de Minas Gerais, Minas Gerais, 2012.

SOUZA, V. C.; RIPPER, Thomaz. Patologia, recuperação e reforço de estruturas de concreto. São Paulo: Editora Pini, 1998.

VAN ACKER, Arnold. Manual de sistemas pré-fabricados de concreto. Bélgica, 2012. 